\title{
Rethinking the language of substance abuse
}

\author{
Matthew C. Fadus, MD
}

n December 2019, Seattle Seahawks wide receiver Josh Gordon was suspended indefinitely from the NFL for violation of the league's substance abuse policy. Gordon, once known as one of the most promising wide receivers of the last few decades, had a tumultuous relationship with the NFL as a result of his struggles with substance use. However, the headlines from major sports and news outlets often describe Gordon and other professional and collegiate athletes who struggle with substance use as "violating policies of abuse." Media coverage of such athletes frequently imposes labels such as "violation" and "abuse," implying a greater level of personal responsibility and willful misconduct than the biological process of addiction would typically allow. Gordon's story brought attention not only to the adversity and impairments of substance use, but also the stigmatizing language that often accompanies it.

\section{Shifting to less stigmatizing terminology}

In DMS-5, use of the terminology substance use disorder fosters a more biologicallybased model of behavior, and encourages recovery-oriented terminology. ${ }^{1}$ However, for most collegiate and professional sports leagues, the policies regarding substance use often use the term substance abuse, which can perpetuate stigma and a misunderstanding of the underpinnings of substance use, insinuating a sense of personal responsibility, deliberate misconduct, and

criminality. When an individual is referred to as an "abuser" of substances, this might suggest that they are willful perpetrators of the disease on themselves, and thus may be undeserving of care. ${ }^{2}$ Individuals referred to as "substance abusers" rather than having a substance use disorder are more likely to be subjected to negative perceptions and evaluations of their behaviors, particularly by clinicians. ${ }^{3}$

Individuals with substance use disorders are often viewed more negatively than individuals with physical or other psychiatric disorders, and are among the most stigmatized and marginalized groups in health care. ${ }^{4,5}$ Today, lawmakers, advocates, and health care professionals across the country are working to integrate destigmatizing language into media, policy, and educational settings in order to characterize substance use as a neurobiological process rather than a moral fault. ${ }^{6}$ For example, legislation in Maine passed in 2018 removed references to stigmatizing terms in policies related to substance use, replacing substance abuse and drug addict with recovery-oriented terminology such as substance use disorder and person with a substance use disorder. ${ }^{7}$

continued

LET YOUR VOICE BE HEARD

CURRENT PsyChIATRY invites psychiatry residents

to share their views on professional or clinical

topics for publication in Residents' Voices.

E-mail jbauer@mdedge.com for author

guidelines.

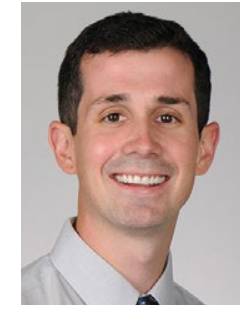

Dr. Fadus is a Child and Adolescent Psychiatry Fellow, Massachusetts General Hospital, Boston, Massacusetts.

\section{Disclosure}

The author reports no financial relationships with any companies whose products are mentioned in this article, or with manufacturers of competing products. 


\section{Clinical Point}

\section{Words matter, and if we are not careful, the language we use can perpetuate the stigma that prevents many patients from accessing treatment}

Individuals with substance use disorders often fear judgment and stigma during clinical encounters, and commonly cite this as a reason to avoid seeking care. ${ }^{8}$ Words matter, and if we are not careful, the language we use can convey meaning and attitudes that perpetuate the stigma that prevents so many from accessing treatment. ${ }^{9,10}$ Individuals with a substance use disorder should feel institutionally supported, and the language of policies and the clinicians who treat these patients should reflect this as well.

\section{References}

1. Diagnostic and statistical manual of mental disorders, 5 th ed. Washington, DC: American Psychiatric Association; 2013.

2. Wakeman SE. Language and addiction: choosing words wisely. Am J Public Health. 2013;103(4):e1-e2.

3. Kelly JF, Westerhoff CM. Does it matter how we refer to individuals with substance-related conditions? A randomized study of two commonly used terms. Int J Drug Policy. 2010;21(3): 202-207.
4. Corrigan PW, Kuwabara SA, O'Shaughnessy J. The public stigma of mental illness and drug addiction: findings from a stratified random sample. Journal of Social Work. 2009;9(2): 139-147.

5. Barry CL, McGinty EE, Pescosolido BA, et al. Stigma, discrimination, treatment effectiveness, and policy: public views about drug addiction and mental illness. Psychiatr Serv. 2014;65(10):1269-1272.

6. Office of National Drug Control Policy. Changing the language of addiction. https://www.whitehouse.gov/sites/whitehouse. gov/files/images/Memo $\% 20-\% 20$ Changing $\% 20$ Federal $\% 20$ Terminology $\% 20$ Regrading $\% 20$ Substance $\% 20$ Use $\% 20$ and $\% 20$ Substance\%20Use\%20Disorders.pdf. Published January 9, 2017. Accessed June 8, 2020.

7. Flaherty N. Why language matters when describing substance use disorder in Maine. http://www.mainepublic.org/ post/why-language-matters-when-describing-substanceuse-disorder-maine. Published May 16, 2018. Accessed June 8, 2020.

8. Merrill JO, Rhodes LA, Deyo RA, et al. Mutual mistrust in the medical care of drug users: the keys to the "narc" cabinet. J Gen Intern Med. 2002;17(5):327-333.

9. Yang LH, Wong LY, Grivel MM, et al. Stigma and substance use disorders: an international phenomenon. Curr Opin Psychiatry. 2017;30(5):378-388.

10. Broyles LM, Binswanger IA, Jenkins JA, et al. Confronting inadvertent stigma and pejorative language in addiction scholarship: a recognition and response. Subst Abus. 2014; 35(3):217-221. 